\section{Petrographic Mineralogy}

By Dr. Ernest E. Wahlstrom. Pp. vii +408. (New York: John Wiley and Sons, Inc.; London : Chapman and Hall, Ltd., 1955.) 62s. net.

DROF. E. E. WAHLSTROM'S "Petrographic Mineralogy" is intended to bridge the gap which exists between text-books that explain the theory of the polarizing microscope and other instruments used in a petrographic laboratory, and those that describe the classification and properties of rocks and minerals.

The subjects dealt with in the first five chapters are the various petrographic methods and techniques that a student should know how to use, and they range from notes about the correct method of collecting and sampling rocks to detailed instructions for the use of the universal stage. The various optical, physical and chemical methods commonly used in the identification of minerals (excepting the goniometer) are all referred to, the emphasis being on identification in thin slice. The next two chapters describe the rockforming minerals under two headings-silicates and non-silicates. Chapter 8 contains tables for the identification of minerals. The last three chapters deal with the composition, properties and classification of igneous, sedimentary and metamorphic rocks. All this matter is comprised within a book of rather less than four hundred pages, so that there is necessarily much eompression; but the large number of explanatory line-diagrams and of photographic reproductions of rock-sections goes far towards compensation for this brevity.

This book is obviously designed to be placed in the hands of students after a preliminary term or two of instruction in the theory and use of the petrographic microscope. Such students, armed with this text-book, might then be expected to make good progress with a minimum of supervision-a great advantage, no doubt, in large classes. Used intelligently, and with aid of the references to further sources of information placed at the end of each chapter, it should fulfil the author's intention successfully.

\section{Soil Zoology}

Proceedings of the University of Nottingham Second Easter School in Agricultural Science, 1955. Edited by D. Keith McE. Kevan. Pp. xiv $+512+16$ plates. (London: Butterworths Scientific Publications; New York: Academic Press, Inc., 1955.) 55s.

$$
T^{\mathrm{s}}
$$

HE study of the fauna of the soil has lagged far behind the study of its chemical and physical properties. The aim of the organizers of the second Easter school in agricultural science, held in Nottingham last year, was to direct attention to this deficiency. Those soil workers who had in the past neglected the fauna because they were unfamiliar with the methods of the zoologist had an opportunity at Nottingham to obtain instruction on the principles of animal identification and on various techniques, as well as hearing more specialized papers describing research on the soil fauna. This information is now made more widely available by the publication of the proceedings, edited by D. K. McE. Kevan.

There are contributions by workers from the Continent of Europe, including Kühnelt, Kubiena, Tischler, Haarløv, Overgaard Nielsen and Brauns, as well as workers in Britain. The contents are divided into two parts. Part 1, which occupies twothirds of the volume, contains twenty-six papers on identification, general biology, ecology and applied aspects. Part 2 contains twenty-five papers describing methods of soil sampling, culturing, preserving and mounting animals, soil sectioning after impregnation with agar, and certain physiological techniques.

In an appendix, Mr. Kevan has included a useful key to the major groups of soil and litter animals. This key occupies thirty-six pages of small type and contains numerous line diagrams. There are a good general index, an author index, and indexes to the genera of animals and plants mentioned in the text.

$$
\text { L. H. Finlayson }
$$

\section{Introduction to Physical Geology}

By Prof. Chester R. Longwell and Prof. Richard Foster Flint. Pp. $\mathrm{x}+432$. (New York : John Wiley and Sons, Inc.; London : Chapman and Hall, Ltd., 1955.) 40s. net.

T might be expected that a book from the pens of 1 two such experienced geologists and teachers as Profs. C. R. Longwell and R. F. Flint would be outstanding in quality, and this one does not disappoint. It develops the basic principles of the science by means of a careful examination of field evidence and also with the aid of a very large number of illustrations, including several instructive air photographs, many of which will be new to British readers. An important feature of the book is the care which has been taken to make these illustrations intelligible to the inexperienced readers for whom it is intended.

An unusual feature is the inclusion of brief references to the history of the subject, indicating to thoughtful readers that many of the conclusions which he tends to accept as axiomatic were only arrived at after much hard thought. The authors quote, for example, Shakespeare's lucid exposition of the cause of eartbquakes, which expresses, not a playwright's fancy but a view held in his time and for centuries earlier.

The book embodies a wealth of experience, principally that of its authors, but also that of many others whom they consulted while writing it. It will prove a very useful addition to the departmental libraries in universities, and in schools in which geology is taught.

\section{Discoveries and Inventions of the 20th Century}

By J. G. Crowther. Fourth edition, entirely revised and rewritten. Pp. xvii $+432+64$ plates. (London: Routledge and Kegan Paul, Ltd., 1955.) 30s. net.

A LTHOUGH this fourth edition has been entirely A revised and rewritten, Mr. J. G. Crowther has retained the general form of the third edition. Some chapter headings have been changed and much new material incorporated, covering inventions and developments of the past twenty-five years. Whethel this is now quite appropriate is a matter of opinion; but the treatment of plastics appears to have been prejudiced by the arrangement, and in this edition is quite inadequate. Something should have been included on the advances in medicinals during this period, if only because of the far-reaching effects of the control of malaria, trypanosomiasis and other killing diseases.

Criticism of omissions, however, is invidious and, apart from these two features, the book gives a com: prehensive and readable picture of the discoveries and inventions of the past fifty years. Of minor slips, attribution of the invention of chromatography solely to Tswett instead of to Runge and others may. be mentioned.
R. B. 